\title{
Measuring the Direct Cost Burden of Illness in Burkina Faso
}

\author{
Ousmane Traoré ,** $^{*}$ \\ ${ }^{1}$ Department of Economics (UFR/SEG), Université Ouaga II (UO2), 12 P.O BOX 417 \\ Ouagadougou 12, Burkina Faso \\ *Corresponding author: Tel: 226-7015-2100Ｅ-mail: oustraor@yahoo.fr
}

Received: August 31, 2018 Accepted: September 27, 2018 Published: December 18, 2018

doi: 10.5296/rae.v10i4.14078 URL: https://doi.org/10.5296/rae.v10i4.14078

\begin{abstract}
In this article, we evaluate the direct cost burden of illness in Burkina Faso. The methodological approach predicts the normative health expenditure based on the population's health risk factors and adjusts the income based on people's asset portfolios, which are supposed to influence their ability to manage shocks, or their vulnerability to shocks like illness. Thus, using the National Institute for Statistics and Demography's priority surveys database of 1996, our methodology leads to a better information on the distributions of income and health care spending across a subsample of 1022 treated individuals. Subsequently, the average of the direct cost burden of illness is $11.17 \%$, and $50 \%$ of the population spend more than $10.52 \%$ of their adjusted income on normative health care. Otherwise, there is a difference of 66.84 of percentage points between the highest and lowest cost burdens. Overall, women face higher direct costs burden compared to men. Given the "catastrophic health expenditure" threshold conventionally set at 10\% of income, to decrease these financial vulnerabilities and inequalities in Burkina Faso, one solution would be to achieve universal health coverage.
\end{abstract}

Keywords: Health, Normative expenditure, Adjusted income, Cost burden 


\section{Introduction}

In the quest to create a financially sustainable health system, most developing countries have opted for a collection system based on direct payment from patients. Thus, notwithstanding the existence of a non-generalized insurance mechanism, out of pocket remains the most important mode of financing health care in these countries. In this context, households generally face increasing difficulties paying for the health services they require. The poorest households must devote so much of their income to the payment of these services that they fall into severe poverty. The evolution of the households' budget allocated to health care beyond a threshold can have severe implications on the other areas of consumption and, consequently, cause costs in economic activity (Russell, 1996). The direct cost of illness on an agent can be evaluated through the proportion of health expenditure in his income. For Russell (2005), the proportion of health care expenditure in a household's income helps evaluate the economic burden of its health care expenditure. So, the proportion of the households' income allocated to health care expenditure is an indicator that must reflect the cost of the appropriateness of the health care expenditure and the households' capacity to satisfy the other basic needs. Thus, the direct costs of illness should be used as basic indicators in the implementation of health policies and budgetary planning. The purpose of these policies, other than to provide access to health care, can be to reduce the level of such costs, that is, to reduce the socioeconomic vulnerability of populations affected by disease. Kifman and Roeder (2011) argue that an optimal insurance policy may be defined according to the thresholds of the proportion of health care expenditure in households' income. Thus, in some insurance scheme, when an agent's health care expenditure exceeds a given threshold, the government may decide to grant him a subsidy. Therefore, measuring the direct costs of illness becomes a major concern.

Many papers have examined, in various health systems, the socioeconomic vulnerability of households in terms of the so-called "catastrophic health expenditure." These catastrophic expenditures are identified from direct calculation of the proportions of health expenditure in household income or the evaluation of the share of health expenditure in the household's consumption budget. The WHO (2000) propose a more refined indicator by changing the income denominator to that remaining after basic consumption needs have been met (capacity to pay). Then, a health expenditure burden greater than $40 \%$ or $50 \%$ of capacity to pay is assumed to be catastrophic for households. By contrast, Ranson (2002) defines a disastrous health expenditure as the expenditure representing a proportion of at least $10 \%$ of a households' income. These definitions assume that beyond the critical thresholds, any health care expenditure creates a cost in terms of consumption, namely, debt, and is consequently a source of impoverishment among the population. Some researches, particularly Wagstaff and Doorslaer (2003), Su, Kouyaté, and Flessa (2006), Xu, Evans, Carrin, Aguilar-Rivera, Musgrove, and Evavs (2007), have focused on the determinants of households' disastrous health care expenditure measured as an arithmetic ratio between the observed health expenditure and household income.

These approaches of estimating the share of health expenditure in household income, have in common the consideration of health expenditure and household income as given variables or 
data that are, therefore, independent of the behavior of economic actors or contexts. Since then, studies have dealt with households' health care expenditure and income as data, namely, purely exogenous variables. We assert that the use of such an estimation of the proportion of health expenditures in household income to analyze catastrophic health expenditures, the unsustainability of these expenditures, or the direct cost burden of illness is incorrect and could skew any health policy based on such indicators. Stam (2007) establishes that the observed health expenditures may contain either over-consumption or under-consumption bias. So information based on the risk factors must be used to calculate the "normative health expenditure" for analysis focused on health expenditure. Moreover, the observed income does not take into account people's asset portfolios, which are supposed to influence their ability to manage, or their vulnerability or resilience to shocks like illness. Therefore, measuring the direct costs of illness must be a major concern in a health system. It may aim to optimal policy implementation and budget planning in a health system and better rationalization of public expenditure (e.g., subsidies to vulnerable groups).

The main objective of this article is to address the direct cost burden of illness calculation. For that, we consider the Burkina Faso and specifically we use econometric models to predict the normative health expenditure based on the population's health risk factors and to adjust the income based on people's asset portfolios, which are supposed to influence their ability to manage, or their vulnerability or resilience to shocks like illness. The paper is organized as follows. Section 2 describes the methodological approach. Section 3 describes the data used for the analysis. Section 4 presents and discusses the results. Section 5 concludes.

\section{Methodological Approach}

\subsection{Adjusted Income Modeling}

Income-based poverty approaches have been criticized for not capturing the range of resources and strategies that people mobilize to access commodities and manage shocks such as illness (Russell, 2005). Sen (1981), Drèze and Sen (1989) established that an individual's access to commodities, or their entitlement set, is determined by income and a range of production, exchange, and transfer processes including government services. People's asset portfolios that include, in particular, policy-derived resources and less tangible assets like social relationships, also influence their ability to cope, or their vulnerability or resilience to shocks like illness (Swift, 1989; Moser, 1998).

Therefore, to consider these realities in an evaluation of the proportion of income allocated to health care expenditure, we will use the income predicted values. These predictions come from the estimation of the observed income ( INC) over a certain number of instruments, as aforementioned. Thus, our model of income estimation is based on the instrumental variables approach of Paxon (1992):

$$
I N C_{i}=\alpha_{0}+\sum_{i=1}^{I} \alpha_{i} X_{i}+\theta_{i}
$$


The vector $X$ comprises the sex; age; health status; variables of permanent income, namely, ownership of cattle; type of building; variables of affiliation to a social security organization, namely, National Social Security Fund, Independent Civil Servants' Pension Fund and insurance. These variables are used as representations of government services and, to some extent, social relationships. The health care status is evaluated according to the score principle of the general health questionnaire of Goldberg, in which the indicators being considered are the area of residence, type of place of ease, evacuation mode of garbage, and drinking water supply mode. This variable is supposed to capture the effect of illness or deterioration of the state of health on household income.

\subsection{Normative Health Expenditure Modeling}

Su, Kouyaté, and Flessa (2006) argue that cost analysis and cost-effectiveness analysis are the essential tools to imply the equitable provision of services, evaluation of disease control programs, and long-term sustainability of healthcare services. In addition, Kell, Savage, Rafiq and Mazzocato (2017) indicated that in modern competitive reimbursement environments, providers and policy makers are looking for cost-accounting solutions capable of informing process improvement and meeting the expectations of cost-control policies.

To address these specificities of cost analysis in relation to health expenditure, we make use of the "normative expenditure" approach. Namely, the costs of services according to the quality, intensity, and level of health treatments considered reasonable (Van de Ven \& Ellis, 2000). Consequently, we can formulate a specification model of normative expenditure. Stam (2007) justifies that, in general, for the definition of the normative expenditure, we can use any type of regression; thus, it is possible to apply any type of estimator by using any available database. By following Stam (2007) we formulate the following equation of the normative expenditure.

$$
Y=\beta_{0}+\sum_{k=1}^{K} \beta_{k} F_{k}+\varepsilon
$$

Where $Y$ illustrates the health care expenditure of the individuals in the entire database, and $F$ is the vector of the individuals health risk factors. In accordance with Van de Ven and Ellis (2000), we choose the age, sex, marital status, health status, handicap, socioprofessional category, cost of care per region, and resort to practices of expensive treatments as potential factors of variation of the individual's health care expenditure.

The cost of care per region expresses the characteristics specific to that region, for example, a difference in the prices or production costs of medical treatments. In this article, the cost of treatment by region is an interactive variable derived from the access time to the health district crossed with the type of locomotion used. The type of locomotion used to get to a health district in interaction with the time of ride gives an indication of the regions' characteristics. Resorting to treatment practices or providers of services that increase the prices are also viewed as an insignificant determinant of health care expenditure. This situation concerns the recourse of choosing private medical doctors and private nurses in this study. 


\section{Macrothink}

When studying health expenditure for a given sample of a population, there can be many people with null health care expenditure, exposing either cases of absence of disease or the lack of access to treatment. This scenario requires preliminary treatment of such data for any analysis.

Thus, to predict the normative expenditure, we adopt the two-stage-estimation method with logarithmic transformation of expenditure, because of the quality of this method in relation to the other estimation techniques of health care expenditure (Manning, 1998). Next, to deal with the heteroscedasticity of health care expenditure, we use the smearing factor as a non-parametric estimator of the error variance, developed by Duan (1983).

The first stage of the model estimates the probability of positive expenditure: $\operatorname{Prob}(Y>0)$. The second stage predicts the unconditional normative expenditure, presented as $E(Y / F)$ by multiplying the expectations of conditional expenditure, namely, $E(Y / F, Y>0)$ through the probability of the first stage. Hence, the following formula:

$$
E(Y / F)=Y^{N O R M}=\operatorname{Prob}(Y>0) \cdot E(Y / F, Y>0)
$$

with $E(Y / F, Y>0)=\exp \left(F \beta+\frac{1}{2} \sigma^{2}\right)=\exp (F \beta) \cdot\left(\frac{1}{N} \sum_{i=1}^{N} \exp \left(e_{i}\right)\right)$ where $e_{i}$ is the error term in the $\log$ regression of positive expenditure $(\log (Y>0))$ on the risk factors and $\left(\frac{1}{N} \sum_{i=1}^{N} \exp \left(e_{i}\right)\right)$ is the smearing factor.

Hence,

$$
E(Y / F)=Y^{\text {NORM }}=\operatorname{Prob}(Y>0) \cdot \exp (F \beta) \cdot\left(\frac{1}{N} \sum_{i=1}^{N} \exp \left(e_{i}\right)\right)
$$

Following the different predictions of the income and normative expenditure, we obtain a sample on which we conclude the proportions of the health care expenditure in the households' income as follows:

$$
\gamma_{i}=\frac{y_{i . h a t}^{N O R M}}{I N C_{i . h a t}}
$$

where $I N C_{i . h a t}$ is the income predicted from equation (1) and $y_{i . h a t}^{\text {NORM }}$ the prediction of health expenditure from the normative specification of health expenditure in equation (3).

\section{Data}

Scarcity of cost data from low- and middle-income countries has severely affected realistic planning and policy decisions to increase healthcare demand and, simultaneously, financial 
protection (Su, Kouyaté, \& Flessa, 2006, Russell, 2004). We use data from a Burkina Faso survey on the living conditions of households in 1996. These surveys were conducted by the Institute of Statistics and Demography. The relative old age of the data, notwithstanding, increases the choice of instruments for our two approaches based on prediction methods.

Table 1 presents descriptive statistics of health care expenditure. The household data concerning the health care expenditure per individual are conducted during the 15 days preceding the survey. The descriptive statistics form of the sample's health care expenditure certifies a very well distinct asymmetry and skewness with a predominance of null values of health care expenditure.

Table 1. Descriptive Statistics of Health Expenditure

\begin{tabular}{ll}
\hline \multicolumn{2}{c}{ Health care expenditure } \\
\hline Mean & 6065,3579 \\
Mode & 0,00 \\
Std. Dev. & 14091,67919 \\
Skewness & 16,276 \\
Kurtosis & 432,680 \\
Min. & 0,00 \\
Max. & 425000,00 \\
Median & 2800 \\
$N$ & 1861 \\
\hline
\end{tabular}

Source: Author.

\section{Results and Discussions}

\subsection{Income Prediction}

The estimation results of the income prediction model (equation 1) are presented in the Appendix 1. Figure 1 below compares the distribution of the income being observed with the predicted income from the results in Appendix 1. Notably, the predicted income has more precise distribution than its observed value. This phenomenon proves the robustness in the use of such predicted income values for our analysis. The distribution is spread to the right with the central parameters located more toward the origin of the reference. The Figure 1 reflects the low incomes and inequalities in the distribution of these incomes in Burkina Faso. 


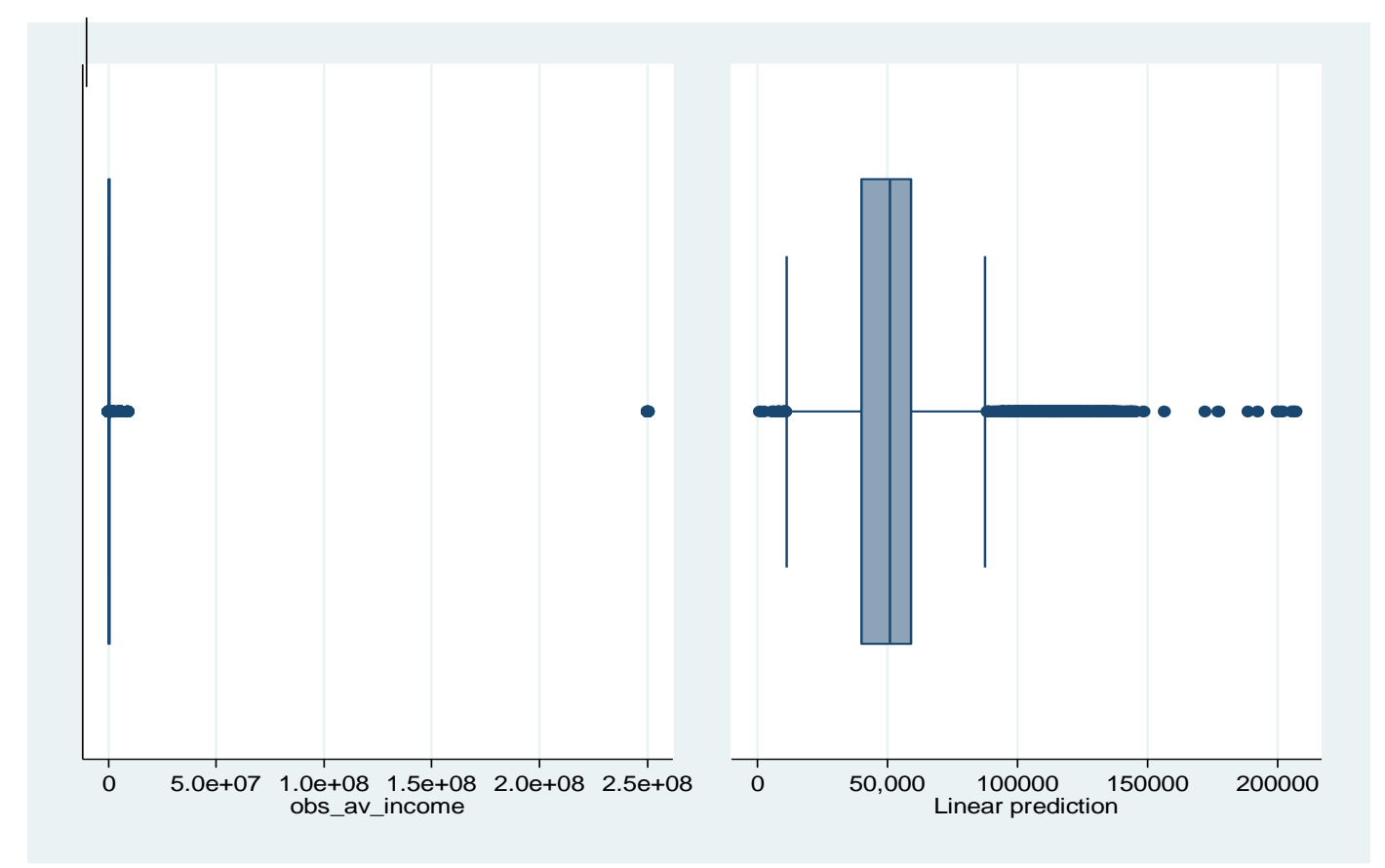

Figure 1. Distributions of the Observed and Predicted Income

Notes: obs_av_income means observed income

\subsection{Prediction of Normative Expenditure}

The prediction of normative expenditure is determined from the estimation of the first stage of the model (2), namely, the probability of positive expenditure followed by the estimation of conditional expenditure. The estimation results of this first part are presented in the Appendix 2. According to White (1982), Aguirregabiria \& Mira (2007), Bajari, Hong, Krainer, \& Nekipelov (2010), the two-stage-estimation approach applies in a case where the first stage regressors (the probability model) are discrete or continuous, and the estimation of this first stage does not require a correct specification of the model. The unconditional predictions of normative expenditure ( $Y^{\text {NORM }}$ in the equation 3 ) are presented in Appendix 3.

The parameters of the predicted normative expenditure are more precise, contrary to those of the observed health expenditure (see in figure 2 below). Overall, figure 2 shows a slightly left-spread distribution with central tendency parameters to the right (high values of health expenditure). The extent of this distribution also reveals a high dispersion of household health expenditure inequalities. 


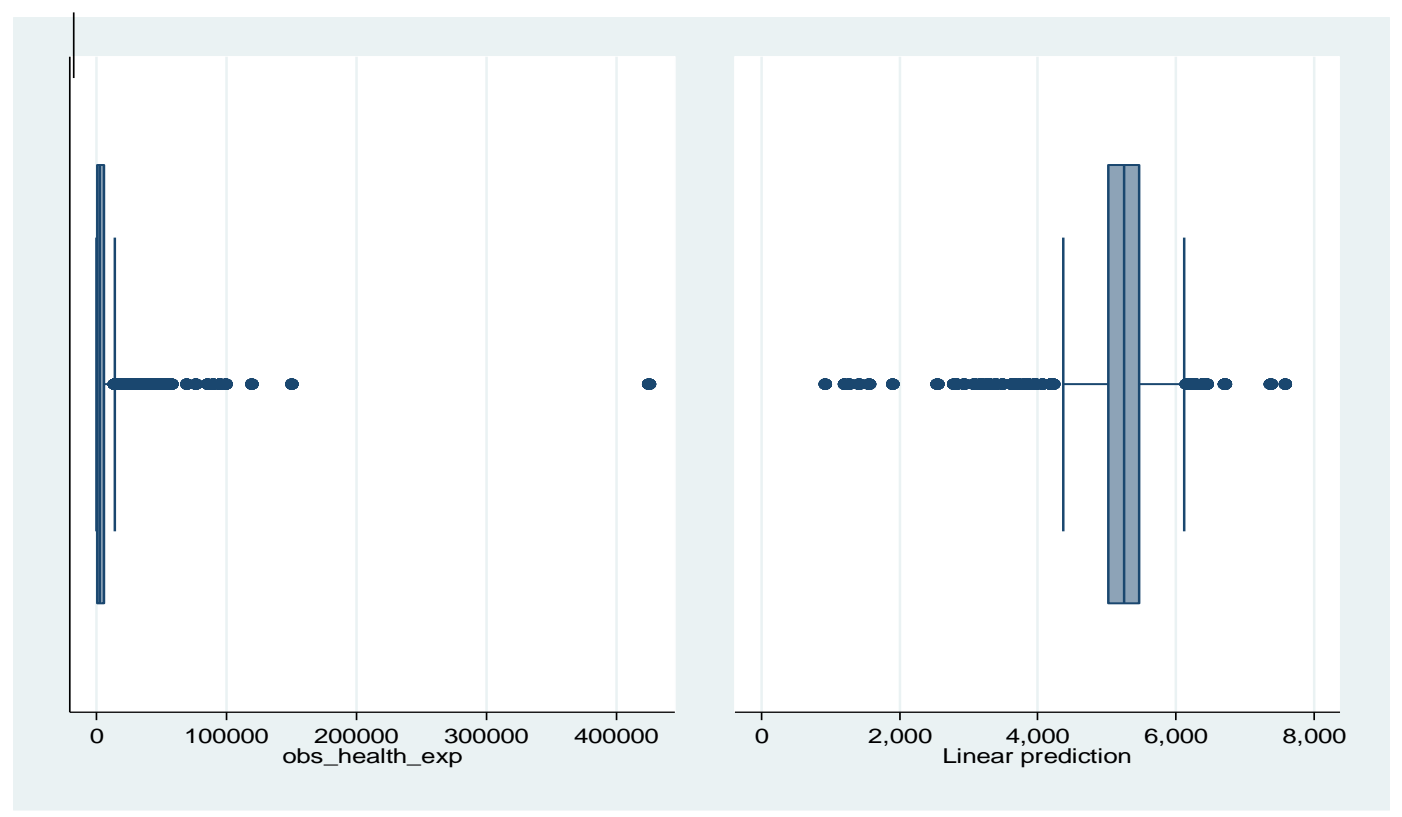

Figure 2. Distributions of Observed and Normative Health Expenditure (Linear Prediction).

Notes: obs_health_exp means observed health expenditure (i.e., health expenditure of the sample)

\subsection{Calculation of the Proportion of Health Expenditure}

We made calculations of direct costs burden of illness (the proportions of normative health expenditure in the predicted income), from the subsample obtained with our approaches. The appendix 3 synthetizes the values of these costs to certain disintegrated values of the risk factors. The proportion of women's health care expenditure in the income, for all age ranges, is generally higher than men's, of which the proportion is less than $10 \%$.

Table 2 below synthetizes the direct costs burden of illness for the whole subsample. On average, each agent devotes $11.17 \%$ of its income to health care expenditure, and $50 \%$ of the individuals devote more than $10.52 \%$ of their income. These results mean that more than $50 \%$ of individuals experience catastrophic health spending, for with the conventional threshold is $10 \%$ of income. The extreme shares of health expenditure in household income are $2.23 \%$ and $69.07 \%$. These results indicate the unsustainable nature of health spending in Burkina Faso and the existence of strong inequalities of health care spending in the population. 
Table 2. Distribution of Normative Health Expenditure as a Proportion of Predicted Income

Descriptive statistics of $\gamma$ (correct proportion of health expenditure in income)

\begin{tabular}{ll}
\hline Mean & 11,17 \\
Std. Dev. & 4,62 \\
Min. & 2,23 \\
Max. & 69,07 \\
Median & 10,52 \\
$N$ & 1022 \\
\hline
\end{tabular}

Source: Author.

Subsequently, Figure 3 below compares the distribution of the proportion of normative health care expenditure in the predicted income to that obtained from both observed health care expenditure and income. The former distribution, the most precise one, is more spread out to the right with a fairly large dispersion. This presentation means that the majority of households in the sample face a high direct cost burden. Moreover, the result proves the existence of inequality between households in the face of the disease. As a whole, our methodology of illness' direct cost burden calculation leads to a better knowledge of distributions of health care spending and income across the population.

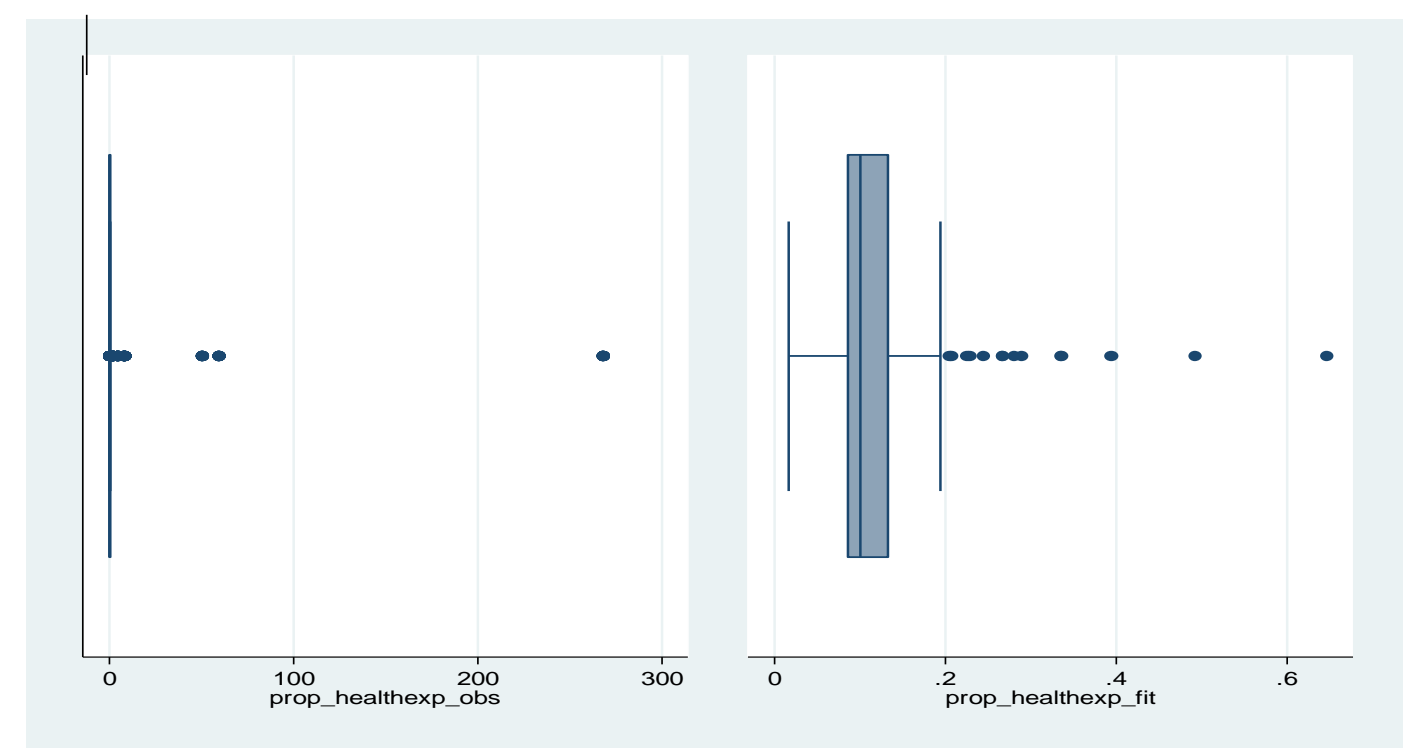

Figure 3. Distributions of the Observed and Predicted Proportions of Health Care Expenditure

Note: prop_healthexp_obs means the proportions of health expenditure calculated with both observed health expenditure and income. prop_healthexp_fit means the proportions of health expenditure calculated with normative health expenditure and predicted income. 


\section{Conclusion.}

Health care expenditures are the primary concern for organizations that promote health care and for health policy makers. A satisfactory evaluation of the proportion of health care expenditure in households' income is, in this respect, crucial for defining fair or sympathetic access policies and budgetary planning regarding health treatment. This article aims to calculate the direct cost burden of illness based on prediction models and better knowledge of distributions of income and healthcare spending in a population. So the approach uses the concept of normative health expenditure, instead of observed expenditure, and predicted income based on people's asset portfolios that include policy-derived resources and assets such as social relationships, which are supposed to influence their ability to manage or their vulnerability or resilience to shocks like illness. From this perspective, this article assesses the use of direct cost burden as an indicator (proportion of health expenditure in household income). This article makes a valuable methodological contribution, is relevant to future empirical work, and has political implications for the health system. Our results reinforce and prove that universal health insurance in Burkina Faso is required to reduce the high vulnerability of households. More than $50 \%$ of households face disastrous health care expenditure, namely, they devote more than $10 \%$ of their income to pay the incurred costs. Our study has a number of limitations that concern essentially the lack of suitable data on detailed health risk factors such as the diagnostic cost group and the pharmacy cost group. These risk factors are useful, in the determination of normative health expenditure.

\section{References}

Aguirregabiria, V., \& Mira, P. (2007). Sequential estimation of dynamic discrete games. Econometrica, 75(1), 1-53.

Bajari, P., Hong, H., Krainer, J., \& Nekipelov, D. (2010). Estimating static models of strategic interactions. Journal of Business \& Economic Statistics, 28(4), 469-482.

Drèze, J., \& Sen, A. (1989). Hunger and public action. Oxford: Clarendon Press.

Duan, N. (1983). Smearing Estimate: a nonparametric retransformation method. Journal of the American Statistical Association, 78, 605-610.

Keel, G., Savage, C., Rafiq M., \& Mazzocato, P. (2017). Time-driven activity-based costing in health care: A systematic review of the literature. Health Policy, 121(7), 755-763. https://doi.org/10.1016/j.healthpol.2017.04.013

Kifmann, M., \& Roeder, K. (2011). Premium Subsidies and Social health insurance: substitutes or complements? Journal of Health Economics, 30(2011), 1207-1218. https://doi.org/10.1016/j.jhealeco.2011.08.007

Manning, W. G. (1998). The logged dependent variable, heteroscedasticity, and retransformation problem. Journal of Health Economics, 17, 283-295.

Moser, C. (1998). The asset vulnerability framework: reassessing urban poverty reduction 
strategies. World Development, 26, 1-19.

Paxon, C. H. (1992). Using weather variability to estimate the response of saving to transitory income in Thailand. The American Economic Review, 82(1), 15-33.

Ranson, K. (2002). Reduction of catastrophic health care expenditures by a community-based health insurance scheme in Gujurat, India: current experiences and challenges. Bulletin of the World Health Organization, 80, 613-21.

Russell, S. (1996). Ability to pay for health care: concepts and evidence. Health Policy and Planning, 11, 219-237.

Russell, S. (2004). The economic burden of illness for household in developing countries: a review of studies focusing on malaria, tuberculosis and human immunodeficiency rirus/acquired immunodefiency syndrome. American Journal of Tropical Medicine and Hygiene, 71, 147-155.

Russell, S. (2005). Illuminating cases: understanding the economic burden of illness through case study household research. Oxford University Press. https://doi.org/10.1093/heapol/czi035

Sen, A. (1981). Poverty and famines. Oxford: Clarendon Press.

Stam, P., J., A. (2007). Testing the effectiveness of risk equalization models in health insurance. Ph.D. Dissertation, Erasmus University Rotterdam, Rotterdam. Retrieved from http://www.stamonline.nl/phdthesis

Su, T., T., Kouyaté, B., \& Flessa, S. (2006). Catastrophic household expenditure for health care in a low-income society: a study from Nouna District, Burkina Faso. Bulletin of World Health Organization, 84, 21-27.

Swift, J. (1989). Why are rural people vulnerable to famine? IDS Bulletin, 20, 8-15.

Van de Ven, W.P.M.M., \& Ellis, R., P. (2000). Risk adjustment in competitive health planmarkets. In A. J. Culyer \& J. P. Newhouse (Eds), Handbook of Health Economics (pp. 755- 845). Amsterdam: Elsevier Science BV.

Wagstaff, A., \& Van Doorslaer, E. (2003). Catastrophe and impoverishment in paying for health care: with applications to Vietnam 1993-98. Health Economics, 12, 921-934.

White, H. (1982). Maximum likelihood of misspecified models. Econometrica, 50(1), 1-25.

WHO. (2000). The World Health Report 2000. Health systems: improving performance. Geneva: World Health Organization.

Xu, K., Evans D., B., Carrin, G., Aguilar-Rivera, A., M., Musgrave, P., \& Evan, T. (2007). Protecting household from catastrophic health spending. Health Affairs, 4(2007), 972-983. https://doi.org/10.1377/hlthaff.26.4.972 


\section{Macrothink}

Appendix

Appendix 1. Estimation results of income prediction model

\begin{tabular}{ll}
\hline INC & coefficients \\
\hline sex & 18223.1 \\
& $(4309.241)^{* * *}$ \\
age & -20.77243 \\
& $(398.4953)$ \\
age2 & 2.183776 \\
& $(6.473623)$ \\
cnss & 74370.49 \\
& $(7553.925)^{* * *}$ \\
carfo & 60121.51 \\
& $(4547.017)^{* * *}$ \\
cnasur & 144672.1 \\
& $(42662.96)^{* * *}$ \\
carsur & 69458.61 \\
& $(24899.28)^{* * *}$ \\
GHQ & -2862.264 \\
& $(1166.529)^{*}$ \\
irevtran & 1466.717 \\
& 1376.788 \\
building type & -23246.97 \\
livestock & $(5330.731)^{* * *}$ \\
cons & 42.67347 \\
& 27.65797 \\
obs & 61034.01 \\
F( 11. 10160) & $(17127.12)^{* * *}$ \\
Prob > F & 10172 \\
R-squared & 0.0000 \\
\hline & 0.0118 \\
\hline
\end{tabular}

***, **, * Significance at $1,5,10 \%$ respectively. Standard deviations in parentheses. Notes: CNSS: National Social Security Fund; CARFO: Independent Civil Servants' Pension Fund; cnasur: variable for CNSS+insurance; carsur: variable for CARFO+insurance; irevtran: variable for transitory income 
Appendix 2. Results of the Models' Probability of Positive Expenditure

\begin{tabular}{|c|c|c|}
\hline & $\operatorname{Prob}(Y>0)$ & $\log (Y>0)$ \\
\hline Sex & $\begin{array}{l}-0.149 \\
(0.46)\end{array}$ & $\begin{array}{l}-0.028 \\
(0.33)\end{array}$ \\
\hline Marital & $\begin{array}{l}-0.545 \\
(0.91)\end{array}$ & $\begin{array}{c}0.134 \\
(0.90)\end{array}$ \\
\hline Age & $\begin{array}{l}-0.015 \\
(1.09)\end{array}$ & $\begin{array}{c}0.005 \\
(1.29)\end{array}$ \\
\hline Disability & $\begin{array}{c}0.591 \\
(0.50)\end{array}$ & $\begin{array}{l}-0.514 \\
(1.94) *\end{array}$ \\
\hline GHQ & $\begin{array}{c}0.029 \\
(0.29)\end{array}$ & $\begin{array}{l}-0.019 \\
(0.74)\end{array}$ \\
\hline Dcat $^{a}$ & $\begin{array}{l}-0.693 \\
(0.63)\end{array}$ & $\begin{array}{l}-0.194 \\
(0.76)\end{array}$ \\
\hline Dcat5 & $\begin{array}{l}-1.297 \\
(1.09)\end{array}$ & $\begin{array}{l}-1.316 \\
(4.36) * * *\end{array}$ \\
\hline Dcat6 & $\begin{array}{l}-1.548 \\
(1.26)\end{array}$ & $\begin{array}{l}-0.374 \\
(1.07)\end{array}$ \\
\hline Dcat7 & $\begin{array}{l}-1.371 \\
(1.22)\end{array}$ & $\begin{array}{l}-0.481 \\
(1.39)\end{array}$ \\
\hline Dcat8 & $\begin{array}{l}-0.102 \\
(0.28)\end{array}$ & $\begin{array}{l}-0.208 \\
(2.10)^{* *}\end{array}$ \\
\hline Dcat9 & $\begin{array}{c}0.702 \\
(1.32)\end{array}$ & $\begin{array}{l}-0.123 \\
(0.99)\end{array}$ \\
\hline Regcost & $\begin{array}{l}-0.005 \\
(0.45)\end{array}$ & $\begin{array}{l}-0.011 \\
(3.23) * * *\end{array}$ \\
\hline Behavcost & $\begin{array}{l}-0.263 \\
(1.17)\end{array}$ & $\begin{array}{c}0.065 \\
(0.70)\end{array}$ \\
\hline _cons & $\begin{array}{c}3.608 \\
(2.75)\end{array}$ & $\begin{array}{c}8.067 \\
(24.66)^{* * *}\end{array}$ \\
\hline Log pseudolikelihood & -191.36663 & - \\
\hline Pseudo R2 & 0.0255 & 0.03 \\
\hline$N$ & 1,080 & 1,051 \\
\hline
\end{tabular}

$* * *, * *, *$ Significance at $1,5,10 \%$ respectively. Standard deviations in parentheses. (a) Dcat. is dummy variable of socio-professional categories 
Appendix 3. Prediction of normative health expenditure $y_{\text {hat }}^{N O R M}$ and its proportion $\gamma_{i}$ in income

\begin{tabular}{|c|c|c|}
\hline Variables & $y_{\text {hat }}^{N O R M}$ & $\gamma(\%)$ \\
\hline \multicolumn{3}{|l|}{ Males } \\
\hline $\mathbf{M}<1$ & 4914,564 & 8,61112 \\
\hline M1-14 & 4978,955 & 8,75031 \\
\hline M15-24 & 4886,281 & 8,43912 \\
\hline M25-34 & 4878,794 & 8,8072 \\
\hline M35-44 & 5108,448 & 8,6932 \\
\hline M45-54 & 5415,137 & 9,33355 \\
\hline M55-64 & 5674,587 & 9,08124 \\
\hline M65-74 & 5339,705 & 8,48886 \\
\hline M75-84 & 5583,369 & 8,02942 \\
\hline$M \geq 85$ & 5889,548 & 9,1761 \\
\hline \multicolumn{3}{|l|}{ Females } \\
\hline $\mathbf{F}<\mathbf{1}$ & 5140,691 & 13,53837 \\
\hline F1-14 & 5300,525 & 13,22652 \\
\hline F15-24 & 5492,888 & 14,44904 \\
\hline F25-34 & 5424,132 & 14,07204 \\
\hline F35-44 & 5454,711 & 12,83471 \\
\hline F45-54 & 5432,617 & 13,68262 \\
\hline F55-64 & 5850,266 & 12,86983 \\
\hline F65-74 & 5785,088 & 13,50487 \\
\hline F75-84 & 5922,897 & 12,26445 \\
\hline$F \geq 85$ & 5654,172 & 10,02367 \\
\hline \multicolumn{3}{|l|}{ Marital } \\
\hline Single (0) & 5191,227 & 10,22731 \\
\hline Couple (1) & 5244,688 & 11,61757 \\
\hline \multicolumn{3}{|l|}{ Disability } \\
\hline No $(0)$ & 5276,081 & 11,2336 \\
\hline yes $(1)$ & 3477,159 & 6,71562 \\
\hline \multicolumn{3}{|l|}{ GHQ } \\
\hline$<$ mean & 5298,455 & 10,76405 \\
\hline$\geq$ mean & 5135,436 & 11,59192 \\
\hline \multicolumn{3}{|l|}{ Dcat } \\
\hline none & 5231,011 & 11,1331 \\
\hline $\operatorname{Dcat}_{1}$ (maneuver) & 3092,255 & - \\
\hline Dcat $_{2}$ (apprentice) & 5181,039 & 4,44604 \\
\hline Dcat $_{3}$ (homemaking) & 4907,529 & 4,73906 \\
\hline Dcat $_{4}($ independent) & 5263,092 & 8,5361 \\
\hline Dcat5(other) & 1381,916 & 3,05858 \\
\hline Dcat6(execitive manager) & 5468,615 & 10,81663 \\
\hline Dcat7(senior) & 5000,952 & 10,43586 \\
\hline Dcats(medium frame) & 5260,81 & 11,40822 \\
\hline Dcat9(qualified worker) & 5257,929 & 11,19294 \\
\hline Dcat $_{10}($ semi-skilled worker) & 5244,151 & 11,43506 \\
\hline$N$ & & 1022 \\
\hline
\end{tabular}

Source: Author's predictions using stata. 


\section{Copyright Disclaimer}

Copyright for this article is retained by the author(s), with first publication rights granted to the journal.

This is an open-access article distributed under the terms and conditions of the Creative Commons Attribution license (http://creativecommons.org/licenses/by/3.0/). 